\title{
The Bitter End? The Close of the 2007 SCF Field Period
}

\author{
Arthur B. Kennickell \\ Board of Governors of the Federal Reserve System, Mail Stop 153, Washington, DC 20551
}

\begin{abstract}
Typically, the end of a survey field period is a point when a survey struggles to achieve what is seen as an acceptable response rate. Response is shaped by the decisions of field staff to continue applying effort and respondents to be open to persuasion. The situation is an uncomfortable one in that it is quite difficult to apply measurable standards to the process in a way that can be mapped with any precision into response probabilities. The Survey of Consumer Finances (SCF) has long gone to the bitter end of the field period where the remaining possibilities of completed interviews are very slim, and in doing so has held response rates approximately constant over time. The hope is that this operational approach will allow as much constancy across time as possible in any response biases. Yet this is a costly approach that could not be justified easily if the last cases are not sufficiently different from cases collected earlier. This paper examines the set of the last cases collected for the 2007 SCF and describes the ways in which they differ from ones collected earlier in the field period. Some limited comparisons are also made with the nonrespondents.
\end{abstract}

Key Words: Survey of Consumer Finances, unit nonresponse, response bias, response rates, late cases, field work

\section{Introduction}

Most household field surveys have less than a 100 percent response rate, no matter how much effort is expended toward that end. At some point in a field period, a decision is made to cease work. Ultimately the decision is constrained by the willingness of respondents to be persuaded by any means, but often a perceived balance of costs and benefits is reached before the point of impossibility. At least one of the costs is obvious: Interviews collected late in a field period tend to be relatively expensive, owing to the generally larger amount of effort expended in the attempt to gain the respondents' cooperation. The obvious benefit is that additional cases lower the computed sampling errors of estimates. But there are more subtle potential costs and benefits.

Although many people speak of increased response rates as a pure good constrained only by cost, pursuit of "late" cases may exacerbate any problems of nonresponse biases, have the opposite effect, or have no effect, depending on the variables considered and the mixture of population characteristics among survey participants, potentially available participants, and immovable nonrespondents (see Groves [2006]). There may also be differences in response quality at different phases of field effort, and other operational and analytical constraints may vary in important ways. Only analysis of the data and associated paradata can provide indications of the underlying situations. Where the available information allows a clear identification of nonresponse biases, work could stop at any point when there are sufficient interviews to support the intended analyses. In the absence of such information, it can certainly be argued that pursuit of the highest possible response rate is a risk minimizing strategy. But even where information is only imperfect, there may still be viable arguments for striving for high response rates. Two such arguments are considered here.

First, in repeating cross-sectional surveys where measurement of changes is an important objective, maintaining procedures as constant over time as possible is a critical goal; in particular, maintaining the survey response rate may be seen as an instrument for holding uncorrectable nonresponse biases as close as possible to constant. However, a constant response rate is a goal that often can be achieved in a variety of ways. Only by applying effort in a way that is meaningfully measurable is there a hope of drawing a line that can be matched over time. For the early phases of survey field work, it is relatively straightforward to design procedures to guide and monitor the application of effort; one such approach for the Survey of Consumer Finances (SCF) is discussed below. Beyond that period, however, field work very often becomes much more heterogeneous, as the field staff implements strategies that are increasingly tailored to individual cases. A justification for pursuit of a high and constant response rate is that it should force effort to a high marginal level of difficulty across all incomplete cases. If there are observable signs of the stress induced, that information can be used to select a response rate to target. The closer the target is to the point of impossibility, the clearer should be the signs of stress. It should be noted that this strategy may fail if the behavior of households changes over time in ways that affect the relative propensities to respond.

The second argument is related. If field staff sense that response rates are not important, their behavior may well change in such a way as to alter the relationship between response rates and nonresponse bias that would otherwise have obtained. Absent some guidance to staff on the desired intensity of effort directed toward specific 
cases, interviewers will naturally tend concentrate on ones that are easiest for them to target, thus yielding a sort of convenience sample. Relatively high response rates may be a means for survey managers to signal the credibility and quality of their work when it is not possible to characterize latent nonresponse bias in a transparent way.

The $2007 \mathrm{SCF}$, which forms the empirical basis of this paper, ran unusually long in the field. Interviewing began in May of 2007, but did not end until March of 2008. Although some special circumstances explain part of this time, it is clear that the level of difficulty of gaining cooperation was higher than in any previous survey. Although the response rate for the survey was held close to the previous level, this effort came at a large cost in terms of money and timeliness. For these and other reasons, examination of the informational value of the final set of cases is important. In the results presented, substantial differences emerge between the late cases and those collected earlier in the field period. This work follows on earlier analysis of late respondents in the SCF reported in Kennickell [1999]. It should be seen as preliminary to a larger work addressing the dynamics of response over the entire field period and the potential implications of those dynamics for nonresponse bias in aspects of key variables.

\section{A Brief Literature Review}

Among the earliest work on interviews late in the field period, Politz and Simmons [1949] and Deming [1950] framed the issues in terms of the difficulty of contracting the respondents. If contacting difficulties alone determined nonresponse and late cases were the most difficult cases to contact, then the late cases could serve as a reasonable proxy for nonrespondents. Stinchcombe et al. [1981] presented evidence from a survey that respondents who are difficult to contact are not unlike the earlier respondents, but that those who gave a "temporary refusal" at some point have a different pattern of data. Smith [1984] argued for consideration of both contact difficulty and uncooperative behavior. Many other papers have been written about the factors driving participation late in a field period and the potential effects of such cases on survey estimates.

More recently, Bates and Creighton [2000] and Duhart et al. [2001] provide evidence from a variety of source to characterize systematic differences in late interviews. Voigt et al. [2003] finds some weak evidence of differences. Curtin et al. [2000] argued that in the survey they consider efforts toward a high response rate did not yield cases that were meaningfully different from earlier cases. Although this last paper carefully qualities its findings as specific to the particular analysis, it has been used by others to argue that response rates do no matter. Of course nonresponse bias that is more important than the response rate (given that there are enough completed cases to perform any analysis), but arguing that response rates do not matter at all is simplistic.

\section{Background on the SCF}

Table 1: Percent distribution of final outcomes of cases, 2007 SCF AP sample.

Complete by phone

15.88

Complete in-person

34.59

Conversion, completed by phone

Conversion, completed in-person

Completed by proxy

Vacant or seasonally vacant housing unit

Sample incorrect

Deceased

Final refusal

Final break-off

Final refusal by gatekeeper

Final unlocatable

Unavailable during field period

Non-Spanish language barrier

Too ill or disabled

Final other nonresponse

Other non-interview

Stopped work

Memo items:

Number of observations released to field
The SCF is a triennial survey conducted by the Federal Reserve Board to collect information on the assets, liabilities, income and other financial and demographic characteristics of U.S. households (see Bucks et al. [2006] for an overview of the data and the technical details). Data for the survey are collected by NORC at the University of Chicago. The survey employs a dual-frame sample to provide sufficient representation of wealth, which is highly skewed in its distribution, as well as characteristics more broadly distributed (Kennickell [2001]). One part is a list sample selected from statistical data derived from tax returns, using a stratification technique to progressively oversample wealthy households. The other part is a multi-stage national area-probability (AP) sample that selects each household with equal probability. To avoid the special complications involved in pursuing very wealthy households - a topic that merits its own analysis - this paper uses only cases derived from the AP sample.

The AP sample released to the field contained 5,001 cases (table 1). Of these, about 14 percent were determined to be out of scope. The response rate (proportion of in-scope cases completed) was about 68 percent, which is a level that has held with relatively small variation since the 1989 survey.

Respondents were given a choice between telephone and in-person interviews, and over a third were interviewed by 
Figure 1: Cumulative distribution of completed cases and noninterviews; by week of the field period; 2007 SCF AP sample.

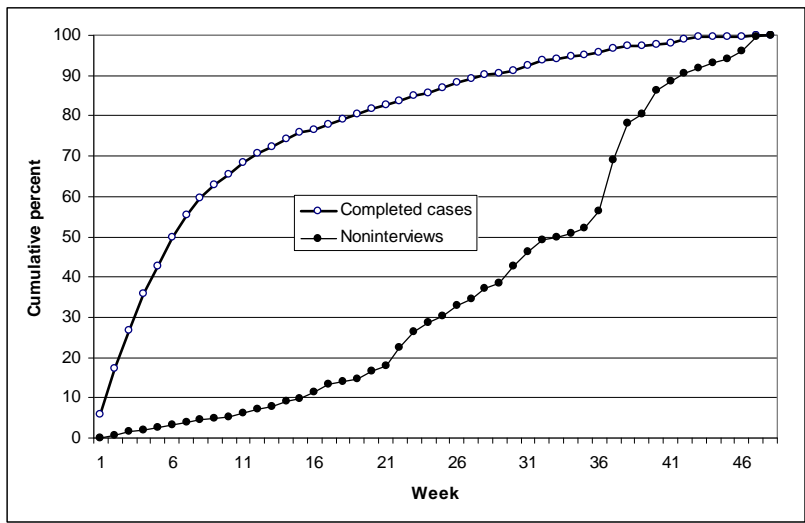

Figure 2: Completed cases and noninterviews as a percent of cases without a final status, 2007 SCF AP sample.

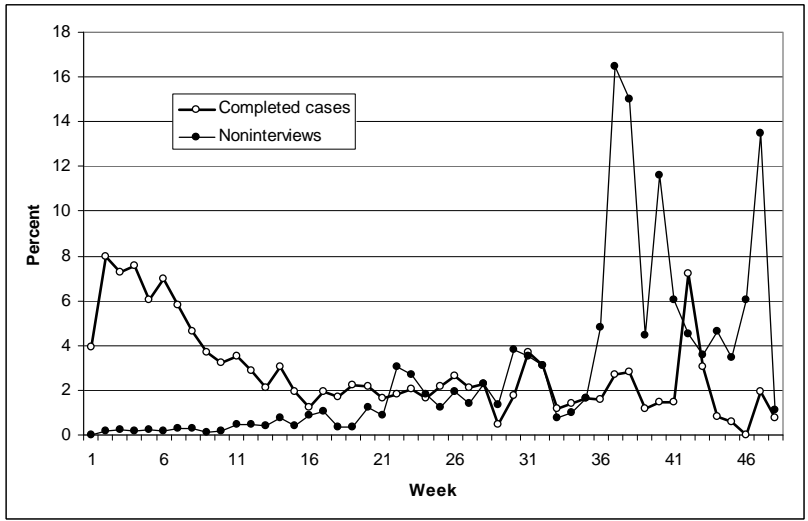

Table 2: Percent distribution respondent gift, by month of interview, 2007 SCF AP sample.

\section{Month of Amount of respondent fee}

\begin{tabular}{lcccccc} 
interview & $\$ 0$ & $\$ 20$ & $\$ 50$ & $\$ 100$ & $\$ 200$ & $\$ 300$ \\
\hline May & 8.6 & 91.3 & 0.1 & 0.0 & 0.0 & 0.0 \\
June & 7.8 & 68.3 & 23.8 & 0.1 & 0.0 & 0.0 \\
July & 10.2 & 22.2 & 63.0 & 4.7 & 0.0 & 0.0 \\
August & 6.5 & 15.2 & 64.7 & 13.6 & 0.0 & 0.0 \\
September & 6.8 & 15.4 & 35.2 & 42.6 & 0.0 & 0.0 \\
October & 6.3 & 0.7 & 12.0 & 80.3 & 0.0 & 0.7 \\
November & 1.0 & 0.0 & 1.0 & 98.0 & 0.0 & 0.0 \\
December & 0.9 & 0.0 & 0.0 & 50.0 & 49.1 & 0.0 \\
January & 1.4 & 0.0 & 0.0 & 38.4 & 60.3 & 0.0 \\
February & 0.0 & 0.0 & 0.0 & 41.0 & 24.6 & 34.4 \\
March & 0.0 & 0.0 & 0.0 & 35.7 & 0.0 & 64.3 \\
\hline & & & & & &
\end{tabular}

telephone. The median interview required approximately 82 minutes; the $95^{\text {th }}$ percentile of the distribution was 150 minutes. Particularly complex interviews were sometimes conducted over many sessions. The interview was available in both English and Spanish, but the Spanish version was not available until September 2007.

Field work ran from about the beginning of the second week of May 2007 until about the end of the third week of March 2008, a period of more than 10 months. But about half of the interviews completed were done by the end of the sixth week and about 90 percent before the $28^{\text {th }}$ week (figure 1). As one might hope, the distribution for final noninterviews is much more stretched out. The dynamics may be more clearly seen in terms of the hazard rates for completion or final noninterview (figure 2) - that is, the percent of cases with as yet undetermined final status achieving a final status in a given period. After an initial spike in the rate of completed interviews, the hazard for completed interviews falls steadily to about one percent by the end of the fourth month and then trends down slowly until the end of the field period. The pattern of final noninterviews shows a rise to about two percent by the end of the fourth month followed by a noisy trend higher. A very complex set of operational decisions underlies these patterns.

The SCF employs a formal three-phase contacting strategy to guide the application of field efforts (Kennickell [2006]). In the first phase, at least the initial attempt to reach the household is made in person; a maximum number of subsequent attempts at varying times are allowed to gain the respondent's cooperation. If the respondent is contacted and does not agree to participate or if the interviewer cannot contact the respondent in the allotted number of attempts, a carefully designed and tailored informational package is sent to the household by express mail. The second phase allows a limited number of follow-up attempts. The third phase pools all remaining cases for further systematic and individual evaluation. The field managers have authority to delay the transition of cases between phases where there is a specific justification.

Initially, all the AP sample cases were offered $\$ 20$ as thanks for participation in the survey, though a small fraction of completed cases apparently declined any amount (table 2). The amount offered tended to rise throughout the field period; in the last partial month, 5 of the 14 completed cases were given $\$ 100$ and the remaining cases were given $\$ 300$. The decision to offer these amounts was strongly driven by the field staff. Although the level of payments rose higher than in previous rounds of the survey, the pattern of escalation is similar. 


\begin{tabular}{|c|c|c|c|c|c|c|c|c|}
\hline \multicolumn{3}{|c|}{ Week of first contact } & \multicolumn{3}{|c|}{ Max. \# weeks between attempts } & \multicolumn{3}{|c|}{ Max. \# weeks between contacts } \\
\hline & Early & Late & & Early & Late & & Early & Late \\
\hline 0 & 0.0 & 0.0 & 0 & 20.8 & 0.4 & 0 & 65.1 & 6.5 \\
\hline 1 & 14.7 & 6.5 & 1 & 27.0 & 0.0 & 1 & 15.4 & 12.9 \\
\hline 2 & 19.5 & 12.2 & 2 & 15.6 & 1.1 & 2 & 6.0 & 8.2 \\
\hline 3 & 13.9 & 8.2 & 3 & 9.8 & 0.4 & 3 & 3.7 & 8.6 \\
\hline 4 & 12.2 & 10.0 & 4 & 7.5 & 3.9 & 4 & 2.8 & 10.8 \\
\hline 5 & 9.3 & 7.9 & 5 & 5.3 & 6.5 & 5 & 1.7 & 8.2 \\
\hline 6 & 8.4 & 7.5 & 6 & 3.1 & 7.9 & 6 & 1.2 & 6.5 \\
\hline 7 & 4.8 & 7.2 & 7 & 2.0 & 8.2 & 7 & 0.7 & 5.4 \\
\hline 8 & 3.3 & 3.6 & 8 & 1.3 & 8.6 & 8 & 0.7 & 3.9 \\
\hline 9 & 2.1 & 4.7 & 9 & 1.3 & 8.2 & 9 & 0.5 & 3.6 \\
\hline 10 & 1.9 & 3.9 & 10 & 0.9 & 7.5 & 10 & 0.3 & 3.9 \\
\hline 11 & 1.9 & 2.2 & 11 & 0.8 & 9.3 & 11 & 0.4 & 6.1 \\
\hline $12+$ & 7.9 & 26.2 & $12+$ & 4.7 & 38.0 & $12+$ & 1.6 & 15.4 \\
\hline
\end{tabular}

Other notable systematic efforts employed in the third phase included the use of a variety of targeted letters, phone calls and a high-level refusal converter. At every step, strong efforts were made to reach the respondent and to communicate the purpose of the survey, the privacy protections, and the flexibility of the scheduling for the interview. As discussed later in this paper, it often appeared at the end of the survey that the most difficult problem was getting the attention of the respondent.

For each case there is a set of call records that was intended to contain an entry for every operation undertaken on the case. Such files were monitored by field managers and the higher-level project staff to ensure that cases were worked as expected. Near the very end of work, recordkeeping sometimes became less regular; nonetheless, the great majority of actions appear to have been recorded. There is also some auxiliary data for each observation, obtained from a match of the sample cases to tract-level data from the 2000 Census of Population. Finally, for completed cases there is the information on the assets, liabilities, income, and demographic and financial characteristics of the households.

\section{4. “Late” Respondents}

This paper focuses on comparisons of AP interviews that were completed relatively late in the field period with the set of such interviews completed earlier. The late cases are taken to include interviews completed from the $28^{\text {th }}$ week of the field period to the end. Of the 1,276 cases still in play during this five-month period, 277 were completed, 656 were registered as final noninterviews during the period and another 343 were assigned a final noninterview code at the close of the field period. Not surprisingly, the late cases were more likely to have expressly declined participation at some point: 63.1 percent of the cases completed late had previously refused, compared with 16.2 percent of the cases completed earlier.

Distinct differences between the early and late cases appear in the patterns of work on these cases (table 3). Attempts to reach respondents began as soon as a trained interviewer was present in the appropriate sample area. From the coded information in the call records, it appears that the late cases were more difficult to contact, whether because they were busy with other activities or because they were avoiding the interviewer. Over a quarter of the late cases were not even contacted (where "contact" is construed broadly to include even mailings beyond the initial pre-filed mailing) until after the twelfth week of the field period, in contrast to only about 8 percent of the early cases. Because the formal contacting strategy normally requires reasonably expeditious work toward at least a contact by express mail in the first phase, this pattern also suggests that there may have been special circumstances or difficulties (e.g., residences with restricted entrance, inadequate locating information, respondents known to be absent, limited interviewer availability, etc.) that caused the field supervisor to delay the work. The patterns of relatively wider gaps for the late cases in attempts to contact the respondent and the consequent gap in the contacts reflect, in part, the fact that many of the late cases were "put on hold" in the third phase of the contacting strategy while other cases more likely to cooperate were pursued.

The late cases were costly. Of the more than 40 thousand attempts recorded for the full AP sample, over half were associated with cases that were still being worked in the late period. But this figure gives a misleading impression of the marginal cost of continuing work from the $28^{\text {th }}$ week; a smaller, but still disproportionate, share of the total 
attempts, 17 percent, was made in this period. However, the overhead per completed interview rose substantially across the field period, despite progressive trimming of the field staff.

Particularly as the field period neared the end, interviews were being completed at a very slow drip. Every case still in play was examined individually and the field managers designed highly tailored strategies. Based on the reports from the field and a reading of the call record notes (discussed briefly later in this paper), it appears very likely that it would not have been possible to obtain more than at most a tiny number of additional interviews, unless extreme steps were taken. There is a high degree of confidence that the limits of participation were reached.

\section{Results}

\subsection{Differences in Economic and Demographic Characteristics}

In terms of geographic distribution, the late cases were relatively more concentrated in the western Census region and less so in the northeastern and north central regions than the early cases (table 4); they were also more concentrated in the largest metropolitan areas and less so in non-MSA areas. Comparable data for nonrespondents (not shown in the table) show a pattern intermediate between the early and late cases for the regional distribution, but an even greater concentration in large metropolitan areas than the late cases. In both instances, the nonrespondent distribution differs more from the early distribution than from the late distribution. Unfortunately, for only one other characteristic considered below, census tract median income, is there information available about the nonrespondents.

Respondents who viewed the interviewer or the study with suspicion might reasonably be expected to have been more resistant to participation in the survey. Indeed, the data show that by the interviewers' evaluations, a substantially larger proportion of the late respondents were more suspicious before the interview than was the case for the early cases. However, the differences after the interview was completed were much smaller, as would be expected once the interviewers had a chance to address the respondents' concerns. The late respondents tended to show more moderate interest in the interview than the early ones, almost of fifth of whom were characterized by the interviewers as having a high level of interest. In terms of respondents' understanding and ability to answer the questions in the interview, there was little difference between the late and early cases. However, the late cases were more frequent in their use of records during the interview, a positive sign for data quality.

The pattern of difference between the early and late cases over the age distribution is mixed, with the most striking differences being a higher proportion of late respondents in the group aged 35 to 44 and a lower proportion aged 75 or older. The former group may contain relatively many people who are busy with the advancement of their careers. As is well known, older respondents are more likely to be at home, and thus more available to the interviewers. Late respondents were somewhat more likely to be male than female and were more likely to be married. But the distribution of household size was very similar for the two groups. The data show that late respondents were somewhat more likely to be Hispanic and less likely to be African American than the early group, a difference probably driven in some part by the late availability of the Spanish language questionnaire.

According to respondents' self evaluation, late respondents were somewhat healthier than early ones. Late respondents were more likely to be working and more likely to be working more than a 40-hour week than the early respondents. Early respondents were more likely to come from households where at least one person volunteered an hour or more a week for a charitable cause. These time use differences suggest that there may be a different valuation of leisure time for some members of the early and late groups. There are small differences in the two groups in the proportion that made charitable contributions; the dollar value of such contributions has consistently been a positive correlate of response for the SCF list sample (see Kennickell [2005]),

The differences discussed so far are suggestive, but they do not address directly the effects of cases from the early and late periods on measures of the core variables of the SCF, those related to wealth and income. Information in the original sample design information allows matching to each case the median income of its Census tract as measured in the 2000 Census of Population. The matched medians can be sorted and ranked as percentiles of that distribution, which can then be used to classify early and late respondents in terms of the relative incomes of their neighborhoods. The data show that late respondents are much less likely to live in the neighborhood with the lowest 10 percent of median values and are correspondingly more likely to be in the groups above the median. For this variable, the distribution for the nonrespondents is also observed. ${ }^{1}$ As with the regional differences, the distribution for nonrespondents lies between the early and late cases, but tends to be closer to the latter. However, it should be emphasized that this classification has potential problems as an indicator of respondents' characteristics. The income is

\footnotetext{
${ }^{1}$ Of the nonrespondents, 10.7 percent were in the 0 - 10 group, 21.7 percent in the 10-25 group, 32.9 percent in the 25 50 group, 25.5 percent in the 50-75 group, 7.7 percent in the $75-90$, and 1.5 percent in the $90-100$ group.
} 
a characteristic of the respondents' neighborhoods, not the respondents. Moreover, the tract-level data are seven years out of date; the relative position of some neighborhoods will have changed. Still, it would be surprising if at least some of the effect did not reflect differences among the groups of sample cases. Results for other economic variables for which nonrespondent data are not available confirm the general differences between the early and late cases.

Late cases were more likely to be homeowners than early cases and they were more likely to have spent less than their income over the previous year (i.e., to have been saving). Figures 3-6 show percentage differences in key distributions for early and late cases. The values displayed are the differences in the value at each percentile of the distribution for the early cases minus the corresponding value for the late cases, as a percent of the early value. Except at the top of the distribution, the income of the late cases is shifted to the right of that for the early cases; at the median, the level for the late cases is over a quarter higher (figure 3). The pattern is similar for net worth (figure 4); at the bottom of that distribution, the percent difference turns positive, reflecting lower absolute value of negative net worth among the lower part of the distribution for the late cases than for the early cases. At the median, the net worth of the late cases is more than 50 percent larger than that of the early cases. Gross assets show a similar picture of higher values except at the top of the distribution (figure 5). For debt, the entire distribution with positive debt is shifted to the right for the late cases (figure 6).

If late respondents tended to provide worse data than earlier respondents, the argument for pursuing such cases would be weakened. Although, as already noted, the late respondents were more likely to use records, their interviews actually tended to be shorter - a mean of 92 minutes for the early cases and 85 minutes for the late cases. Yet comparison of the number of missing dollar values in the data after editing (a step that tends to generate additional missing values when the data are poorly collected) shows a substantially lower rate of missing data for the late cases (table 5). ${ }^{2}$ The best interviewers were the ones selected to continue working in the last months of the field period; thus, this higher level of data quality may reflect the behavior of the interviewers, characteristics of respondents, or both.

\subsection{Information from Call Record Notes}

While interviewers were documenting the actions taken on each of their cases, they had the opportunity to add descriptive notes that might be helpful if the case were transferred or if there were problems. Virtually all the cases still active in the late part of the field period had extensive notes associated with them. There is a great and colorful variety of particular circumstances, but there are common themes within this group.

Many cases show strong evidence of being difficult to reach. Often it was the initial contact with the respondent that was hard to arrange, but recontact appears to have been even more difficult in most cases. Some respondents actively evaded the interviewer, by being unavailable, by not answering the door or the telephone, by hanging up the phone before speaking, etc. In a large fraction of the cases worked in this period, the respondent was genuinely busy - with work, children, grandchildren, travel, friends, etc. In very many instances, the interviewer simply did not have a chance to explain the key details about the study until quite late, if even then. A large fraction of the respondents made it clear that they did not recall reading any of the materials they had been mailed or that had been left with them.

For those who did engage with the interviewer at all, as nearly all would ultimately if sometimes only briefly, three key points of cover virtually all of the resistance: insufficient interest in the subject, the length of the interview and skepticism about the confidentiality of the information requested. A much smaller number seemed to have a particular resistance to requests from the government. When the interviewer had the opportunity to engage with the respondent, all of such issues could be addressed. For many cases in the late group, that opportunity came only when the respondent got the information (most often in a very hastily delivered phone message or a letter sent by express mail) that a substantially larger respondent fee was being offered.

From informal notes, it is impossible to know for certain how each of the respondents reacted to the amount offered. For some respondents, it is clear that they wanted money and they simply sold their time for the interview; others may have been in the camp of "partial gifts" well known in the museum world. But for many others it appears that the function of money was to surprise the respondent into a state where the interviewer could deliver a clear description of what was being asked, the motivation for it, and the strong steps taken to ensure the confidentiality of the data. In many cases the interviewer noted the respondent had effectively been entirely uninformed other than being aware that someone was attempting to get them to take part in a survey. This does not argue that the money itself may not still have been important, but it does suggest that there may be more efficient means of reaching some of the group.

\footnotetext{
${ }^{2}$ A variable is counted as missing if its value is a formal missing value code ("don't know" or "refuse") or if it is not known whether the question should be answered or not as a result of a higher-order missing value (for example, a single missing value for a question about pension ownership could imply as many as 23 missing dollar values).
} 


\begin{tabular}{|c|c|c|c|c|c|}
\hline Characteristic & Early & Late & Characteristic & Early & Late \\
\hline Region & & & R's marital status & & \\
\hline Northeast & 18.0 & 15.8 & Spouse or partner present & 57.4 & 63.1 \\
\hline North central & 24.5 & 19.4 & No spouse or partner & 42.6 & 36.9 \\
\hline South & 36.1 & 35.8 & Household size & & \\
\hline West & 21.5 & 29.0 & 1 & 24.3 & 23.8 \\
\hline Type of area & & & 2 & 33.3 & 34.3 \\
\hline Largest MSAs & 39.8 & 43.0 & 3 & 18.4 & 18.1 \\
\hline Other MSAs & 22.9 & 22.2 & 4 & 13.4 & 14.8 \\
\hline Non-MSA & 37.3 & 34.8 & 5 & 6.8 & 5.8 \\
\hline $\mathrm{R}$ suspicious before interview & & & $6+$ & 3.8 & 3.3 \\
\hline Not at all & 56.3 & 28.5 & $\mathrm{R}$ 's race/ethnicity & & \\
\hline Somewhat & 33.2 & 43.0 & White non-Hispanic & 71.6 & 72.0 \\
\hline Very & 10.5 & 28.5 & African American & 12.8 & 9.0 \\
\hline $\mathrm{R}$ suspicious after interview & & & Hispanic & 11.9 & 14.7 \\
\hline Not at all & 86.1 & 83.4 & Other & 3.7 & 4.3 \\
\hline Somewhat & 12.7 & 15.2 & R's health & & \\
\hline Very & 1.3 & 1.4 & Excellent & 28.0 & 32.1 \\
\hline $\mathrm{R}$ 's interest in the interview & & & Good & 48.3 & 50.5 \\
\hline High & 19.8 & 10.5 & Fair & 18.5 & 14.1 \\
\hline Above average & 33.2 & 27.8 & Poor & 5.2 & 3.3 \\
\hline Average & 40.2 & 57.0 & Number of hours worked by R & & \\
\hline Below average & 6.7 & 4.7 & None & 32.6 & 25.1 \\
\hline R's understanding of questions & & & $1-10$ & 1.4 & 0.4 \\
\hline Excellent & 48.1 & 50.9 & $11-20$ & 3.7 & 4.3 \\
\hline Good & 43.2 & 41.2 & $21-30$ & 4.7 & 6.8 \\
\hline Fair or worse & 8.7 & 7.9 & $31-40$ & 38.5 & 39.1 \\
\hline R's ability to answer questions & & & $>40$ & 19.2 & 24.4 \\
\hline Excellent & 55.0 & 56.3 & Household volunteered $\geq 1$ hour & & \\
\hline Good & 37.5 & 37.6 & Yes & 26.3 & 22.2 \\
\hline Fair or worse & 7.6 & 6.2 & No & 73.7 & 77.8 \\
\hline $\mathrm{R}$ used records during the interview & & & Household gave $\geq \$ 500$ to charity & st year & \\
\hline Frequently & 9.2 & 10.1 & Yes & 39.5 & 39.8 \\
\hline Sometimes & 15.7 & 21.3 & No & 60.5 & 60.2 \\
\hline Rarely & 12.7 & 10.8 & Median income percentile of cens & tract & \\
\hline Never & 62.4 & 57.8 & $0-10$ & 16.8 & 6.5 \\
\hline R's age & & & $10-25$ & 24.0 & 24.6 \\
\hline$<35$ & 23.4 & 22.9 & $25-50$ & 34.4 & 34.3 \\
\hline $35-44$ & 21.8 & 25.8 & $50-75$ & 19.4 & 25.3 \\
\hline $45-54$ & 20.5 & 18.3 & $75-90$ & 4.8 & 7.6 \\
\hline $55-64$ & 16.7 & 17.9 & $90-100$ & 0.8 & 1.8 \\
\hline $65-74$ & 9.3 & 10.0 & Household spending relative to in & me last & \\
\hline$>=75$ & 8.4 & 5.0 & Spent more than income & 15.6 & 11.9 \\
\hline Sex of respondent & & & Spent about same as income & 29.1 & 22.0 \\
\hline Male & 43.3 & 46.9 & Spent less than income & 55.4 & 66.1 \\
\hline \multirow[t]{3}{*}{ Female } & 56.7 & 53.1 & Housing tenure & & \\
\hline & & & Homeowner & 64.5 & 74.9 \\
\hline & & & Other & 35.5 & 25.1 \\
\hline
\end{tabular}




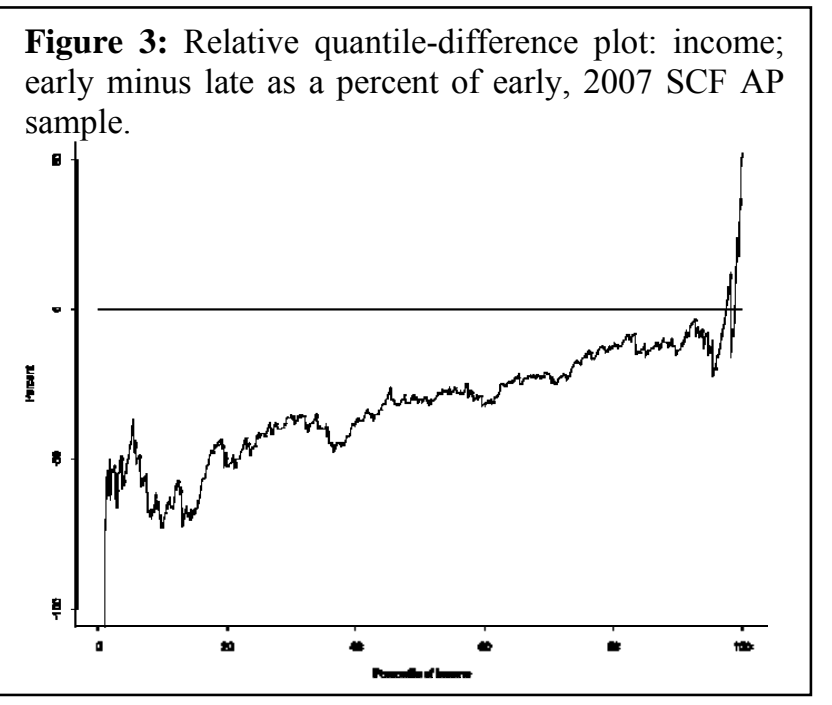

Figure 4: Relative quantile-difference plot: net worth; early minus late as a percent of early, 2007 SCF AP sample.

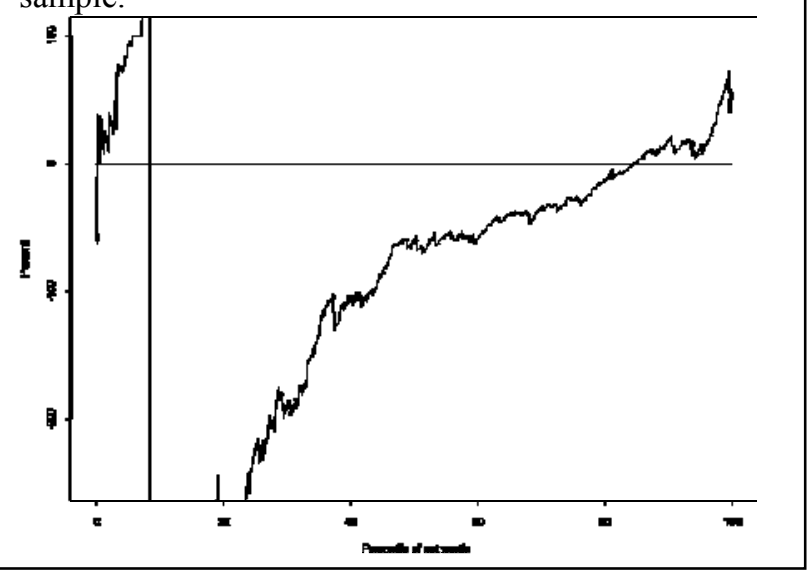

Figure 5: Relative quantile-difference plot: assets; early minus late as a percent of early, 2007 SCF AP sample.

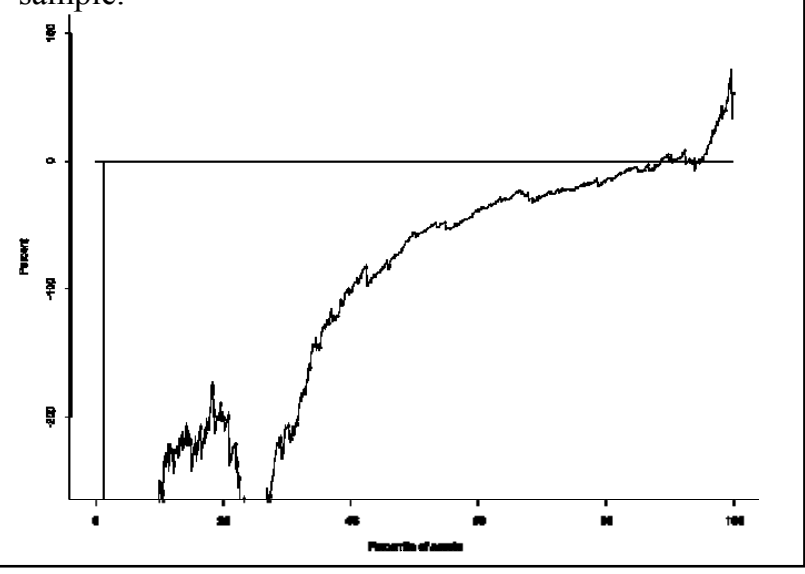

Figure 6: Relative quantile-difference plot: debt; early minus late as a percent of early, 2007 SCF AP sample.

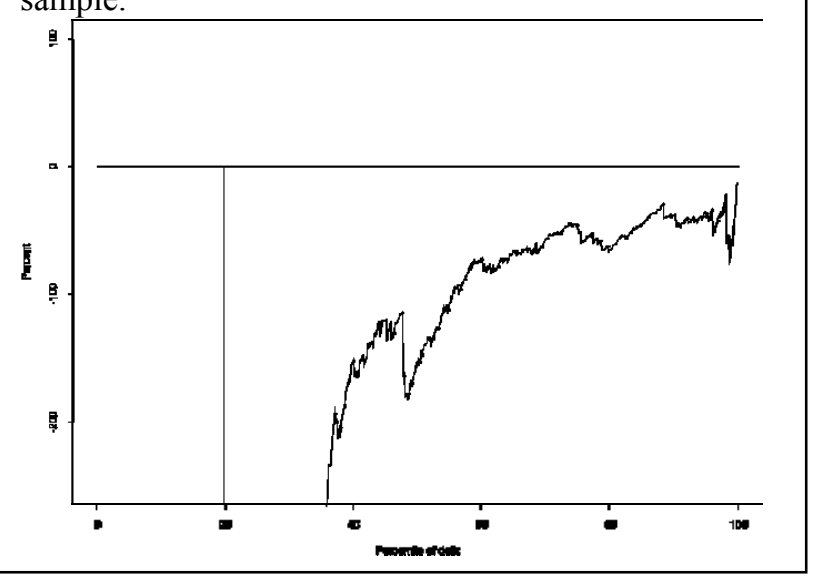

Ultimately, some of the cases worked in the late

Table 5: Percent of applicable dollar values missing after editing, 2007 SCF AP sample.

\begin{tabular}{|ccccc} 
& & \multicolumn{3}{c}{$\begin{array}{l}\text { Percentile of distribution of } \\
\text { percent of missing dollar } \\
\text { values }\end{array}$} \\
& Mean & $50^{\text {th }}$ & $75^{\text {th }}$ & $90^{\text {th }}$ \\
Early & 12.4 & 7 & 18 & 33 \\
Late & 6.9 & 4 & 8 & 17 \\
\hline
\end{tabular}

period did not participate. What appears in the call notes for them seems to differ only in degree, usually strongly so, from the cases that were completed in that period. They are even more difficult to contact, more suspicious, etc. Based on a reading of the notes for those cases, it seems highly unlikely that any of them could have been persuaded to participate without an extreme intervention.

\section{Summary and Future Research}

In surveys where nonresponse is nontrivial, it is worth worrying about cases collected late in the field period for what they may add as information and what they cost in various terms. Where there is ambiguity about nonresponse bias, it may be reasonable to pursue a higher response rate, if only to have the data necessary to evaluate the efficacy of that strategy. In repeated surveys, consistent and high response rates may serve as an instrument for maintaining a relatively constant level of any response biases over time.

The SCF model is to pursue as high and constant response rate over time. This paper shows that in the 2007 SCF there were notable differences between the cases collected late in the field period (from the $28^{\text {th }}$ week to the end) and those collected earlier. The findings are particularly striking for the core economic variables in the survey. Moreover, at least in terms of the limited geographic and neighborhood income data available for nonrespondents, it 
appears that they are more like the late cases than the earlier cases, suggesting that collecting the late interview served to reduce bias in some dimensions.

In the process of developing the results presented in the paper, the group of cases collected somewhat less close to the end of the field period were also considered. In general, the patterns observed relative to the earlier cases were similar to, but weaker than, those for the late cases. Where there is a relatively predetermined structure to effort for the early part of the field work in a survey, as is the case for the SCF, there may be more to learn about the dynamics of participation over the field period. Such research may provide further insights into nonresponse, as well as more effective ways to apply effort.

\section{Acknowledgements}

Opinions presented in this paper are those of the author and they do not necessarily represent the views of the Federal Reserve or its staff. The author thanks Catherine Haggerty, Micah Sjoblom and other staff in the central office of NORC and the very resourceful and energetic field managers and interviewers for their work in collecting the data used in this paper. Thanks to colleagues Brian Bucks, Gerhard Fries, Daniel Grodzicki, Traci Mach and Kevin Moore in the Microeconomic Surveys Section of the Federal Reserve Board for their contributions in processing the data. And above all, thanks to the SCF respondents for their generosity in sharing their time and information.

\section{References}

Bates, Nancy and Kathleen Creighton [2000] "The Last Five Percent: What Can We Learn from Difficult/Late Interviews?" Proceedings of the Section on Government Statistics, pp. 120-25.

Bucks, Brian K., Arthur B. Kennickell and Kevin B. Moore [2006] "Recent Changes in U.S. Family Finances: Evidence from the 2001 and 2004 Survey of Consumer Finances," Federal Reserve Bulletin, pp. A1-A38.

Curtin, Richard, Stanley Presser and Eleanor Singer [2000] "The Effects of Response Rate Changes on the Index of Consumer Sentiment," Public Opinion Quarterly, 64:413-28.

Deming, W. Edwards [1953], "On a Probability Mechanism to Attain an Economic Balance Between the Resultant Error of Response and the Bias of Nonresponse," Journal of the American Statistical Association, v. 48, December, pp. 743-72.

Duhart, Detis, Nancy Bates, Barbara T. Williams and Gregg Diffendal [2001] "Are Late/Difficult Cases in Demographic Survey Interviews Worth the Effort? A Review of Several Federal Surveys," Paper presented at the annual conference of the Federal Committee on Statistical Methodology.

Groves, Robert M. [2006] "Nonresponse Rates and Nonresponse Bias in Household Surveys, Public Opinion Quarterly, 70:646-75.

Kennickell, Arthur B. [1999] "What Do the "Late" Cases Tell Us? Evidence from the 1998 Survey of Consumer Finances," paper presented at the International Conference on Survey Nonresponse, Portland, OR, available at http://www.federalreserve.gov/pubs/oss/oss2/papers/icsn99.9.pdf..

Kennickell, Arthur B. [2001[ "Modeling Wealth with Multiple Observations of Income: Redesign of the Sample for the 2001 SCF," available at http://www.federalreserve.gov/pubs/oss/oss2/papers/scf2001.list.sample.redesign.9.pdf.

Kennickell, Arthur B. [2005] "Darkness Made Visible: Field Management and Nonresponse in the 2004 SCF, available at http://www.federalreserve.gov/pubs/oss/oss2/papers/asa2005.5.pdf.

Kennickell, Arthur B. [2006] "Who's asking? Interviewers, Their Incentives, and Data Quality in Field Surveys" available at http://www.federalreserve.gov/pubs/oss/oss2/papers/iariw.2006.7.pdf.

Politz, Alfred and Wilard Simmons [1949] "An Attempt to Get the 'Not at Homes' Into the Sample Without Callbacks," Journal of the American Statistical Association, v. 44, March, pp. 9-31.

Smith, Tom [1984] "Estimating Nonresponse Bias with Temporary Refusals," Sociological Perspectives, v. 27, no. 4 (October), pp. 473-489.

Stinchcombe, Arthur L., Calvin Jones and Paul Sheatsley [1981] "Nonresponse Bias for Attitude Questions," Public Opinion Quarterly, v. 45, pp. 359-375.

Voigt, Lynda F., Thomas D. Koepsell and Janet R. Daling [2003] "Characteristics of Telephone Survey Respondents According to Willingness to Participate," American Journal of Epidemiology, 157:66-73. 